\title{
Los usos y costumbres de la recepción televisiva en los escolares de Lima metropolitana
}

\author{
Lessy Jakiwara Grández \\ (Universidad Complutense de Madrid)
}

Recibido: 9/11/2012

Aprobado: 14/12/2012

Resumen: En esta investigación se buscó conocer los usos y costumbres de la recepción televisiva de los jóvenes escolares en Lima metropolitana, teniendo en cuenta el tipo de colegio: público o privado. Se realizó en dos momentos y se trabajó con metodología cuantitativa y cualitativa en el año 1997 para observar las semejanzas y diferencias de los resultados. En el año 2009 se realizó una pequeña entrevista cualitativa con la finalidad de conocer la evolución del fenómeno estudiado.

Palabras clave: Televisión / jóvenes / tiempo libre / educación para los medios

\section{The uses and customs of television reception in the high school students of Lima}

Summary: This research sought to understand the uses and customs of the television reception of school youth in metropolitan Lima taking into account: the type of school: public or private. Held at two times and worked with quantitative and qualitative methodology in 1997 to observe the similarities and differences of the results. The year 2009 was a small qualitative interview in order to understand the evolution of the phenomenon under study.

Keywords: Television media / youngers / free time / education for the media 


\section{La televisión como medio de comunicación de masas}

El proceso de masificación del uso de la televisión se ha producido con la finalidad de llegar a una mayor cantidad de público; es una tecnología que ha ido evolucionando y profundizando su uso, perfeccionando sus estrategias publicitarias y variando los formatos de programas. Hemos pasado, pues, de un mundo basado en la lectura y en la argumentación (en la etapa de la preponderancia del libro) a un mundo basado en la imagen, en la apariencia, con la supremacía de la televisión como medio de comunicación por excelencia. En la actualidad, el gran desarrollo tecnológico, la televisión por cable, las videograbadoras y los DVS grabadores, han hecho que los auditorios se desmasifiquen, lo cual incrementa la cantidad de información y busca dirigirse a minipúblicos, cambiando de esta manera la etapa de masificación de los medios de comunicación a una etapa de desmasificación; ello permite una mayor cantidad de gente individualizada, heterogénea, lo cual obliga a los medios de comunicación a buscar intereses de grupos más reducidos y dirigirse a audiencias más locales.

La tecnología ha revolucionado la vida social del hombre desde épocas antiguas hasta la actualidad. Uno de los grandes saltos de época se debió al descubrimiento de la imprenta, que permitió el paso de una sociedad en la cual el conocimiento era un privilegio de unos pocos a una difusión masiva de ideas y conocimientos a través del libro. Otro gran salto, que cambió recientemente el mundo, se da a través del uso de las nuevas tecnologías, que tienen un avance incesante y que van modificando el modo de vida y de relacionarse de la gente. Tiene un peso preponderante en la vida social, ya que condiciona y cambia los modos de vida de la gente; así tenemos que el uso generalizado de la telefonía móvil, inimaginable hace algunas décadas, ha cambiado las formas de comunicación interpersonal y sus aplicaciones tienen ingentes posibilidades por explotar a nivel comercial. Internet y las redes sociales han cambiado, de alguna forma, los modos de relacionarse de muchas personas que utilizan estos medios, logrando construir incluso relaciones de pareja que llegan al matrimonio; a la vez, este tipo de tecnología permite un mayor alcance en cuanto a la distancia para llegar a las personas; sin embargo, permite que la gente se encuentre más sola a nivel personal y pueda mentir más fácilmente que en una interacción "cara a cara», puesto que no podemos ver sus gestos y su comunicación no verbal en general.

También es conocido que estas nuevas tecnologías han permitido la agrupación espontánea de la gente para realizar desde actos triviales hasta manifestaciones de gran importancia social y política. Postman (1991: 83) indica que la tecnología es una ideología porque impone un estilo de vida, de relaciones humanas y un conjunto de 
ideas que se aceptan sin discusión. La tecnología produce cambios sociales; entre estos tenemos los cambios de hábitos cognitivos y las formas de comunicación que se atribuyen a la televisión y a los teléfonos móviles, respectivamente, así como a la participación social del sujeto y el acceso a nuevas formas de percepción.

Postman indica que la imagen visual conspira contra la profundidad de los contenidos de la televisión, pues hemos pasado de una sociedad basada en el conocimiento de lo impreso, que facilita la reflexión, a una sociedad en la que prima la cultura del espectáculo, que privilegia lo emocional y no lo racional; esto tiene influencia en la conversación política, religiosa, informacional y comercial. Añade, además, que en la cultura impresa el lenguaje es más argumentativo; la televisión ha cambiado en la gente este tipo de entrenamiento, pues en general el público cree que lo que ve por televisión es verdad, porque la televisión como medio de comunicación goza de verosimilitud al mostrar los hechos; sin embargo, no se suelen tener en cuenta los sesgos que posee esta imagen. $\mathrm{Al}$ no requerir mayor preparación que la capacidad visual, el acceso a la televisión es casi universal; por otro lado, quiere tener una gran cobertura, pues es una tecnología fundamentalmente comercial que promueve el consumismo, sin tener en cuenta el nivel cultural de las personas; cuanto más personas accedan a la televisión mayores son las posibilidades de negocio de las empresas. «La televisión ha alcanzado el estatus de "meta-medio", es decir, el de instrumento que dirige no solo nuestros conocimientos del mundo, sino también nuestra percepción de las maneras de conocer», señala Postman (1991: 83), y todo lo está convirtiendo en espectáculo, porque busca el entretenimiento de los espectadores, aunque también es cierto que nos permite conocer ciertas realidades mediadas y no pocas veces desinforma o manipula la información, pues tiene un maridaje con el poder político de turno en cada sociedad. Por ello, es importante fortalecer a la sociedad civil, con el fin de contrarrestar la influencia de la televisión mediante una educación para los medios dirigida a los estudiantes de periodismo y periodistas para que ejerzan su práctica profesional con ética, y a la población en general para que puedan tener una actitud más crítica con respecto a lo observado en la pantalla.

La televisión es un medio poderoso de socialización, pues a través de ella el individuo estructura su personalidad para desenvolverse en la vida social; además de un medio tecnológico de producción y transmisión de información, que produce significados y tiene múltiples usos.

Postman afirma también que «[...] la televisión educa, queramos o no, enseña actitudes, que es el capital más importante del ser humano y la televisión enseña a través del aprendizaje colateral y de la experiencia se aprende más» (1991: 152); y precisa- 
mente, en este proceso de educación, casi sin proponérselo, está su mayor influencia, pues construye las expectativas sociales de la gente. Al respecto, Mercedes Charles manifiesta que:

El aprendizaje no requiere intencionalidad. El aprendizaje puede ocurrir sin el objetivo de aprender... aprender no se restringe al uso de elementos racionales. Gran cantidad de lo que los educandos aprenden es a través de las emociones (1990: 71).

Gracias a la influencia de la televisión, se busca el entretenimiento en las aulas, señala Postman que «[...] de acuerdo con los estudios más serios mirar televisión no aumenta significativamente el aprendizaje y es menos probable que cultive un pensamiento de orden elevado y deductivo» (1991: 159); es decir, estaría influyendo en la atención y en los hábitos cognitivos de la gente y de esta manera controla su educación.

En la misma línea, Giovanni Sartori (1997) señala que la televisión influye negativamente en el hábito de la lectura, ha contribuido al empobrecimiento de la capacidad de entender de la gente debido a que, como dice Postman: «[...] la televisión produce imágenes y anula los conceptos y de este modo atrofia nuestra capacidad de abstracción y con ella toda nuestra capacidad de entender» (1991: 47); además, erosiona los contenidos emitidos con la finalidad de llegar a un mayor número de personas, porque es un medio que requiere rapidez y dinamismo, pues los costos de emisión son altos.

La televisión permite que gente con escaso nivel cultural acceda a ciertos contenidos que de otro modo no llegarían; y de esa forma se intenta acceder al nivel cultural medio de la población, por lo que los programas con contenido de interés político, cultural o socioeconómico relevante para el bienestar común se tratan con poca frecuencia y los espacios televisivos de este tipo de programas son reducidos; la televisión apunta a «llenar el tiempo» de la gente como una forma de ocio que se orienta al entretenimiento.

Sartori también señala que la televisión produce «soledad electrónica», porque reduce las interacciones sociales y, de esta manera, desmoviliza y desmotiva a la participación política; en este sentido, Roberto Aparici, Agustín García Mancilla y Manuel Valdivia Santiago indican que la televisión produce un aturdimiento de la conciencia crítica en la sociedad, aunque crea públicos y comunidades de recepción televisiva que constituyen un elemento de vinculación a la vida social.

La televisión permite una actitud pasiva, implica -según Ander-Egguna pasividad corporal, lo cual influye negativamente en la salud de la gente, porque favorece la obesidad y las enfermedades cardiovasculares; además, no tiene feed-back inmediato o retroalimentación en la comunicación, al tiempo que exacerba el consumismo. 
Por su parte, Aparici, García y Valdivia (1992) afirman que está demostrado que la imagen influye más en los telespectadores que los propios contenidos que transmiten; además, acotan que si las personas buscan información en la televisión les va a influir más directamente.

De acuerdo con los citados autores, la internalización que produce la televisión en el proceso de socialización se da porque el individuo acepta la influencia, pues la conducta es coherente con el sistema de valores que tiene. Lazarsfeld y sus colaboradores comprobaron -según Manuel Martín Serrano (1978)- que los mensajes difundidos por los medios son asimilados si refuerzan las actitudes preexistentes.

La televisión cumple diferentes roles: entretiene, informa, relaja, y por tanto es un vehículo para ofrecer recompensas y gratificaciones psíquicas; tendría un efecto catártico en el individuo por la descarga emocional que se da en las comedias y tragedias y un efecto mimético, pues existe un poder imitativo de lo que se ve en pantalla, pero también reduce la capacidad de interacción con otras personas, constituyendo de esta forma un elemento sustancial de su vinculación con la vida social. Puede ser un canal de persuasión y movilización, y hacer que surjan determinados tipos de públicos y mantenerlos; además, maneja un lenguaje polisémico; es decir, es posible atribuir diferentes significados a los contenidos que se emiten, por lo que algunos estudiosos consideran que allí radica su éxito.

Al reducir la capacidad de interacción entre las personas también ha cambiado los hábitos en las familias y ha disminuido la capacidad de creación, análisis y producción de mensajes interpersonales. El éxito de la televisión radica en gran medida en las posibilidades de expansión del mercado, de producir ideas que inducen al consumo. A través de la televisión se accede al conocimiento de las realidades y acontecimientos sociales que no están muchas veces a nuestro alcance a escalas local, nacional y mundial.

Lee Hausner y Jeremy Scholberg nos dicen que:

A la larga, sin embargo, lo peor que la televisión puede hacer en el caso de los niños es darles imágenes hechas, embotando así la capacidad imaginativa del niño, posiblemente de por vida. Comparemos esto con que tengan la oportunidad de formar sus propias imágenes -su propio mundo interiorcuando les leemos algo, o leen ellos o escuchan cintas grabadas con cuentos. Leer o escuchar cuentos proporciona a los niños una mayor sensación de control gracias al estímulo de su imaginación. Basándose en sus experiencias, pueden hacer que los personajes tengan el aspecto que ellos creen que deberían tener (2000: 128-129).

Así, la televisión, entre otros medios, en forma sutil e invisible influye a través de sus contenidos programáticos en la forma como el hombre 
construye y percibe la realidad que lo circunda, y le proporciona elementos para interactuar socialmente, lo que significa que la televisión educa al individuo e influye en su conformación cultural.

La televisión domina tres códigos perfectamente: la imagen (visual), la palabra (oral) y los sonidos musicales y ruidos, en constante y compleja combinación que afecta no solo el aspecto racional sino también el aspecto emocional e inconsciente de todas las personas, más aún si pasan largas horas frente a ella.

Cada cultura codifica sus signos y la forma en que los codifica constituye mapas de significación que los espectadores tienen que decodificar, dicho proceso es complejo y contradictorio. Las audiencias se relacionan a través de la televisión de diversas maneras que no empiezan en la pantalla y que tampoco terminan en ella. La recepción televisiva es un proceso mediado antes, durante y después del hecho de ver televisión y por lo tanto se desarrolla en diferentes escenarios y en él intervienen diferentes agentes.

Por tanto, la televisión tiene como medio de comunicación masivo una gran responsabilidad en la construcción que cada persona efectúa de su realidad inmediata y de sus expectativas sociales; debería estar regulada de manera que sin mellar la libertad de expresión respete a todos los colectivos existentes en la sociedad, como el horario infantil, es decir, el horario libre de imágenes violentas, de sexo y sangre, puesto que las imágenes tienen gran impacto en el aspecto emocional de las personas, por los recuerdos a los que inducen; además, la televisión es una concesión pública, y por tanto debe velar por el bien común.

Internet es un medio de comunicación cuyo consumo ha subido ostensiblemente en los últimos años; la información de todo tipo está cada vez más cerca de las personas, pero mucha de esta información no está legitimada por las personas que la producen, pues no son especialistas en el tema y opinan libremente, sin estar calificadas para ello; es decir, proliferan los contenidos y los emisores, y si bien esto es una forma de democratización de los emisores, sin embargo tiene sus aspectos negativos porque mucha de esa información, sobre todo en cuestiones médicas, es bastante cuestionable. Es interesante que la gente opine libremente sobre temas de interés común en los foros, aunque no todo el mundo está legitimado para hablar de temas especializados.

La recepción es una interacción material, cognitiva y emocional que tiene la posibilidad de optar por la producción de sentido que crea conveniente. Es un proceso mediado que se da antes, durante y después de ver televisión y que cada receptor construye con todas sus mediaciones y sus experiencias previas.

Las mediaciones que se dan en esta recepción son los lugares desde 
los que se otorga sentido a lo que se ve en la televisión. Tienen su origen en diversas fuentes, como los mismos medios, los textos y sus discursos, los lenguajes y dispositivos técnico-informativos, o en los propios miembros de la audiencia, como individuos únicos e irrepetibles y como sujetos sociales contextualizados en su cultura, su historia, las instituciones en las que participan y las situaciones específicas en su interacción con los medios.

Orozco señala que:

La mediación se origina en varias fuentes: en la cultura, en la política, en la economía, en la clase social, en el género, en la edad, en la etnicidad, en los medios de información, en las condiciones situacionales y contextuales, en las instituciones y en los movimientos sociales. También se origina en la mente del sujeto, en sus emociones y en sus experiencias. Cada una de estas instancias es fuente de mediaciones y pueden también mediar otras fuentes. Por ejemplo, las experiencias previas de los sujetos median los procesos cognitivos del sujeto y de su televidencia. Y, al mismo tiempo, el entendimiento del sujeto sobre éstas puede mediar a su vez a la televidencia posterior (1996: 84-85).

La televisión en tanto medio de comunicación masivo, debe contribuir a los procesos de democratización de la sociedad, generando debates de interés general que permitan el acceso a la información de la mayoría de la población sobre los temas de interés económico, político, cultural y social; por tanto, los eruditos que trabajen en los debates televisados podrían actuar como docentes, haciendo accesible este conocimiento a la mayoría de la población, de modo que la gente pueda ejercer su ciudadanía, no solamente a través del voto en las elecciones sino opinando y exigiendo a las autoridades la transparencia y la honestidad en la gestión de los políticos, que tienen una crisis de imagen no solamente por los procesos de corrupción que se dan en diferentes países sino también por la incapacidad que muestran muchas veces para solucionar los problemas de la gente que los ha elegido.

La democratización de las sociedades pasa por la colaboración que la televisión como medio de comunicación masivo ofrezca en este proceso social; pero sobre todo pasa por dotar a los receptores o televidentes de las herramientas necesarias para ser receptores críticos de lo que se ofrece a través de la pantalla, para exigir contenidos de mayor calidad y para influir en la programación televisiva a través de su veto a programas sensacionalistas, en los que muchas veces se atenta contra el honor y la dignidad de las personas.

La democratización de la sociedad, sobre todo con respecto al ejercicio de la ciudadanía, tiene que ver con la educación para los medios, pues la audiencia no tiene el poder real de imponer la programación televisiva que sea relevante a los fines de bien común de una sociedad, es decir, los telespectadores no influyen mayor- 
mente en la agenda setting (temas importantes a tratar en la televisión), sin embargo puede educar e informar de la realidad política, económica y social de cada sociedad con un lenguaje accesible a cualquier ciudadano para que este pueda ejercer sus derechos de manera más informada y consciente; es decir, se podría realizar una alfabetización del mundo audiovisual y de las nuevas tecnologías, que incluyan a las redes sociales.

\section{Hipótesis}

Se planteó la hipótesis de que la recepción televisiva de los jóvenes escolares de quinto grado de secundaria en Lima metropolitana está diferenciada por las comunidades de significación de referencia y el tipo de colegio.

Las comunidades de significación de referencia tienen que ver con las características que distinguen a estas comunidades, como la edad, el género, la clase social, la ubicación geográfica, entre otras.

El tipo de colegio está referido principalmente a la diferenciación que se establece entre colegios privados y públicos, es decir particular o nacional.

\section{Metodología}

En esta investigación se utilizaron las metodologías cuantitativa y cualitativa: se realizó una triangulación de las técnicas con el fin de dar mayor fiabilidad a sus resultados; es decir, se aplicó una encuesta, dos entrevistas en grupo y luego se ha realizó una entrevista personal para comparar los resultados después de más de una década y observar la evolución de los resultados de esta investigación. Se realizaron las encuestas y las entrevistas en grupo en el mes de julio de 1997, con el objetivo de hacer una investigación en los campos cuantitativo y cualitativo; además, se efectuaron las entrevistas semiestructuradas en abril del 2009, con la finalidad de conocer la evolución de este fenómeno teniendo en cuenta la evolución macroeconómica favorable del Perú.

La encuesta se realizó en base a un muestreo probabilístico estratificado no proporcional, pues consideramos que era el que más se ajustaba a los objetivos de nuestra investigación, que buscaba conocer las diferencias entre los estudiantes de los colegios públicos y de los privados. Nuestra encuesta tuvo un nivel de confianza del $95 \%$ y un margen de error del $5 \%$.; tomamos un $10 \%$ más de encuestas con la finalidad de revisar la consistencia interna de las encuestas recogidas; en total se tomaron en cuenta 266 encuestas para procesar los resultados finales de la investigación. Previamente se realizó un pre-test para probar el cuestionario a cincuenta estudiantes que no se consideraron en los resultados finales y que sirvieron para mejorar el cuestionario en los ámbitos semántico y sintáctico. 
Las entrevistas que tienen un enfoque cualitativo se hicieron con la finalidad de conocer mejor las opiniones de los jóvenes estudiantes, aunque se utilizó la encuesta estructurada de 1997, los entrevistados respondieron libremente a las preguntas planteadas y dieron más importancia a algunas preguntas y no contestaron otras debido a que la entrevista discurrió de una manera más natural, casi como una conversación.

Se efectuó una clasificación de los colegios teniendo en cuenta que el criterio principal fue el económico, por la localización de los colegios en barrios residenciales o en periféricos, así como su infraestructura; es decir, la calidad de las instalaciones con que cuentan y el nivel socioeconómico de los alumnos, aunque en los estratos A y B así como en los estratos C y D las líneas fronterizas de delimitación son complejas y a veces borrosas, porque muchos padres se esfuerzan por enviar a sus hijos a colegios privados, con grandes dificultades. En general, para realizar la clasificación de los colegios privados en estratos hemos tenido en cuenta el número de alumnos, el costo de las cuotas por la enseñanza y el nivel académico de estos.

Los colegios de estrato A son colegios privados de gran infraestructura y gran número de alumnado, ubicados en los distritos de La Molina, Miraflores, San Isidro, Surco, Barranco, Surquillo, entre otros; tienen un costo alto de las cuotas de enseñanza, mu- chos de ellos son bilingües y cuentan con un alto nivel académico; asimismo, gozan de un gran prestigio como colegios de élite. Los colegios de estrato $\mathrm{B}$ son centros educativos privados de menor envergadura por infraestructura y población escolar, es decir, son colegios privados más pequeños, con menor infraestructura y prestigio, ubicados generalmente en las zonas residenciales de Lima. Los colegios de estrato C son centros educativos públicos de las diversas zonas de Lima, constituidos sobre todo por las grandes unidades escolares. En estos colegios se ubica la mayoría de estudiantes de las clases media y media baja. Los colegios de estrato D son públicos y se encuentran en las zonas periféricas de Lima (Lima norte y Lima sur), con mayor índice de pobreza, así como en zonas económicamente deprimidas.

Cabe resaltar que las diferencias económicas y de cosmovisión entre los estratos A y B así como C y D son escasas debido probablemente a que el estrato inmediato inferior tiene como grupo de referencia el grupo inmediato superior.

Los grupos de discusión realizado en dos colegios, uno privado de mujeres del estrato $\mathrm{A}$ y otro público mixto del estrato C, en el año 1997, nos permitió confirmar lo que decían nuestras respuestas encontradas en la encuesta respecto a las horas en que los jóvenes estudiantes veían televisión, con quiénes lo hacían, lo que veían, lo que les brinda la televisión, los valores ne- 
gativos que encontraban en sus programas favoritos, los programas que preferían, por qué veían dichos programas y la hora en que lo hacían, la frecuencia con que veían sus programas preferidos, lo cual demuestra que la investigación es consistente, pues coinciden los resultados cuantitativos con los resultados cualitativos.

\section{Resultados de la investigación}

Se observa la fragmentación o segmentación de las audiencias en la recepción televisiva de los jóvenes limeños, lo cual encaja perfectamente con la teoría de Alvin Toffler (1994), que señala que los públicos son cada vez más dispersos debido a su naturaleza y a sus intereses igualmente diversos, así como a la cantidad de emisores, es decir, de canales abiertos y de circuitos cerrados o cables que permiten un mayor número de opciones a los televidentes que tienen la posibilidad de acceder a ellos; este es un dato importante porque vemos que la recepción televisiva juvenil limeña no es ajena a los fenómenos de la desmasificación de las audiencias.

Los jóvenes de clase media y baja ven más horas de televisión diaria porque tienen menos horas de asistencia al colegio que los estudiantes de colegios privados, quienes además tienen otras posibilidades de diversión, como el acceso al teléfono por horas más prolongadas, a la computadora, etcétera.
Los estudiantes ven televisión varias horas al día, todos los días; es decir, hay fidelización de los programas televisivos. Los jóvenes que ven televisión diariamente suelen estar pendientes de sus programas favoritos y dejan otras actividades o seleccionan ese tiempo específico para ver televisión, en cambio los jóvenes que ven sus programas favoritos de manera interdiaria (un día sí y otro no) no están tan pendientes de esos programas.

Ven más televisión solos los estudiantes de los estratos A porque los padres tienen muchas horas de trabajo fuera de casa, al igual que los estudiantes del estrato D por el mismo motivo, aunque los jóvenes del estrato A pueden ver televisión solos también porque poseen más televisores en casa y disponen generalmente de uno en su habitación. El hecho de ver televisión con otras personas ayuda a mediar de otra manera el hecho mismo de ver televisión, pues los comentarios de lo que se ve en pantalla ofrece una mediación diferente que si se ve solo; esto se llama mediación situacional; aunque la mayoría de los estudiantes ven la televisión acompañados (63,2 \%). Orozco afirma que:

Cuando se ve TV sin compañía no se tiene acceso inmediato a la «sanción del otro» sobre lo que se está viendo, lo cual en el caso de los niños pequeños puede ser determinante para su interacción con la TV. Los límites físicos del espacio donde se ve la TV también constituyen un tipo de mediación situacional en tanto que el lugar que 
ocupa el televisor hace posible ciertos tipos de interacción directa e impide otros (1996: 39).

\section{Rosa María Alfaro y Sandro Macassi (1995) señalan que cuando un niño está expuesto a mensajes con- tradictorios sufre inestabilidad; igual- mente es más vulnerable e influencia- ble, porque se encuentra en proceso de aprendizaje y construcción de su personalidad.}

El 75,2 \% de los estudiantes encuestados tiene entre uno y tres televisores. Esto demuestra que la televisión tiene una penetración importante en la vida social limeña; es decir, solamente los muy pobres no cuentan con un televisor en casa.

Las respuestas de que el padre y ellos mismos deciden el programa que se ve en casa quizá tenga que ver con el proceso de afirmación de la personalidad que se da en la adolescencia y también otorga un mayor poder de decisión al padre que a la madre.

El $64,7 \%$ de los estudiantes encuestados ve televisión en la noche, el $26,3 \%$ lo hace en la tarde y el 3,0 \% en la mañana. Ve televisión en otros horarios, que es una combinación de las categorías anteriores el 5,6 \% y no contesta el 0,4\%. El horario de preferencia por la noche se debería a que en el día los jóvenes van al colegio y en la tarde generalmente hacen sus deberes escolares; además, los programas preferidos por los estudiantes se emiten en la noche. Los estudiantes que no ven televisión por la mañana no lo hacen porque acuden al colegio en ese horario. El consumo avanza conforme avanzan las horas del día.

El 46,6 \% ve televisión porque están libres, el 16,5 \% porque están relajados y el $27,4 \%$ por ambas razones, por otros motivos el 9,4\%, y confirman que usan la televisión como una forma de ocio y entretenimiento.

El 3,0 \% de los estudiantes encuestados dice que la televisión brinda relajación, el 13,5\% entretenimiento, el $6,0 \%$ información y el 76,3 \% dice que todas las mencionadas, y no contesta el 1,1\%. Realmente, la televisión cumple perfectamente estas tres funciones principales entre los estudiantes, aunque cada uno utilice más la que considere más importante para su bienestar personal.

El modelo de gratificaciones señala que el televidente busca sobre todo diversión o entretenimiento. Los jóvenes estudiantes, sobre todo los de colegios estatales, no tienen muchas posibilidades de ocio alternativo más saludable, como por ejemplo pasatiempos en los que se les dé la oportunidad de hacer cosas que les resulten gratificantes y sean importantes para la conformación de su personalidad y les sirva para enfrentar su vida futura, estas posibilidades de uso del tiempo libre serían la práctica y promoción del asociacionismo juvenil, el ejercicio del voluntariado, el aprendizaje de cursos que les permitan comprenderse 
y desarrollar sus habilidades: talleres de liderazgo, de literatura, de autoestima, de habilidades sociales, cultura general, educación crítica para los medios de comunicación, entre otros; en suma, formarse para el ejercicio de la ciudadanía a través de una educación moral y cívica así como el desarrollo de la educación emocional para el desempeño en sociedad.

En la etapa de la desmasificación de la televisión hay una dispersión de los programas que se ven en pantalla; esto también tendría relación con la falta de identificación de los estudiantes con los personajes que aparecen en televisión, pues la influencia por menor exposición disminuiría también dicha identificación. Por otro lado, es interesante ver que los jóvenes escolares limeños muestran una gran necesidad de afirmación de sí mismos, quizá sea por la etapa adolescente que atraviesan, y que están en proceso de formar su personalidad adulta.

El $24,4 \%$ no se identifica con su personaje preferido porque no se parece a él, y el 17,7 \% dice "ser él mismo», lo cual muestra el deseo de afirmar su personalidad en esta etapa de su vida.

Se comprueba que el consumo televisivo es diferenciado por los tipos de colegio: público o privado; el promedio de ambos estudiantes en ambos tipos de colegio es similar: de 3 a 5 horas diarias frente al televisor, sin embargo son los estudiantes de colegios públicos los que pasan mayor tiempo viendo televisión, lo cual reduce sus posi- bilidades de crecimiento intelectual, por la «carga pasiva» que ello lleva consigo. Los hombres prefieren ver televisión a la hora que escogen porque están libres y mucho más más relajados que las mujeres; igualmente, ellos escogen ambas razones: están más relajados y libres para ver televisión que las mujeres. Esto nos permite inferir que las mujeres ayudan en las tareas domésticas mucho más que los hombres, lo cual propicia la socialización del hogar machista y reduce las posibilidades de las mujeres de ocuparse de tareas intelectuales o desarrollar otros intereses.

Los estudiantes de colegios privados en general ven menos telenovelas que los estudiantes de colegios públicos, así como los programas deportivos los ven más los chicos de colegios públicos, que son los que más ven los programas deportivos que pueden incitar a la violencia y a las «barras bravas».

Entre los programas que también son preferidos por los jóvenes estudiantes, según el género y el colegio, tenemos que los hombres de colegios públicos prefieren los programas deportivos y las mujeres de colegios públicos prefieren las telenovelas; un grupo numeroso de jóvenes no encuentran ningún valor negativo en el programa que ven, siendo mayor esta actitud en estudiantes de colegios públicos que privados; asimismo, los estudiantes de colegios privados dicen que la codicia y la envidia, la mentira 
y la hipocresía, la ironía y el sarcasmo son los antivalores que con más frecuencia se observan en televisión más que los estudiantes de colegios públicos. Por otra parte, los jóvenes estudiantes de ambos tipos de colegios prefieren la televisión y la radio; en cambio, los jóvenes de los estratos $\mathrm{C} y$ $\mathrm{D}$ de colegios públicos prefieren más la radio.

La televisión se convierte en entretenimiento barato y «muy tenido a mano», los divierte y relaja. Los estudiantes de colegios públicos pueden informarse y culturizarse a través de ella y ver su programa favorito en función a los artistas y cantantes que se presentan en él, así como por el fenómeno del fanatismo que sienten las chicas de colegios públicos por sus ídolos juveniles.

Los anuncios publicitarios preferidos son los que se refieren a bebidas gaseosas, ropa y cerveza; si juntamos los de bebidas gaseosas y de cervezas tenemos que el 32,7\% prefiere este tipo de publicidad; cabe resaltar que son los hombres quienes prefieren los anuncios comerciales de cerveza, debido - según señalan - a que aparecen mujeres en ropa de baño o ceñida.

El doble de mujeres prefiere su programa favorito por los actores y cantantes que los hombres, quienes prefieren sus programas porque los divierte o el argumento les parece interesante. Una cuestión que merece destacarse es el acceso a internet de una manera más notoria en todos los niveles sociales, aunque no haya una difusión masiva de esta en los hogares, sin embargo hay un acceso a través de las cabinas públicas. Se observa, pues, una leve evolución favorable de la situación económico-social.

Las mujeres de colegios públicos encuestadas son quienes ven más telenovelas que no contienen argumentos consistentes y recrean la historia del «Príncipe Azul», que es un arquetipo.

La recepción televisiva de los estudiantes de quinto año de secundaria está diferenciada por las comunidades de significación de referencia, la que está relacionada con la clase social y es un reflejo de la socialización que se da en la realidad social limeña, y a la vez retroalimenta los valores que inculca esta socialización.

El colegio es el reflejo de lo que ocurre en la sociedad, ya que forma parte del sistema social, por tanto, grafica las diferencias sociales y la desigualdad de oportunidades que se produce en la sociedad limeña.

\section{Conclusiones}

La presente investigación tiene entre sus principales conclusiones las siguientes:

1. Que la televisión es el medio de comunicación preferido por los jóvenes escolares en Lima metropolitana, aunque la internet adquiere cada vez más importancia como medio de comunicación, sobre todo 
en los estratos socioeconómicos más altos.

2. Que los jóvenes escolares limeños consideran que la familia es su principal apoyo, y la institución social de la cual reciben la mayor influencia en sus vidas, por lo que es importante no solo de manera figurativa sino como cédula importante del tejido social.

3. Que la televisión es usada fundamentalmente como un medio de entretenimiento, una forma de pasatiempo, sobre todo en los estudiantes de colegios estatales.

4. Que los estudiantes de los colegios particulares encuestados en 1997 tienen una actitud más crítica que los estudiantes encuestados ese mismo año en colegios estatales y que los estudiantes entrevistados en todos los estratos y en ambos tipos de colegio: público y privado, en el 2009, tienen una actitud más crítica que los jóvenes encuestados en 1997.

5. Que la recepción televisiva de los escolares está diferenciada por las comunidades de significación de referencia, la que está relacionada con la clase social y el género.

6. Que los que tienen mayor tiempo de exposición a la televisión son los estudiantes de colegios públicos, porque cuentan con más tiempo libre por una menor presión de rendimiento académico y porque la televisión es una forma de recreación barata y accesible.
7. Que los gustos y las preferencias de los jóvenes escolares están diferenciadas por el tipo de colegio, y tiene que ver con las clases sociales y el género; así, las mujeres de colegios estatales prefieren ver telenovelas y los hombres de colegios estatales prefieren programas deportivos. Asimismo, los estudiantes de colegios privados prefieren ver comedias norteamericanas.

8. Hay una fragmentación o segmentación de las audiencias juveniles limeñas; por tanto, la recepción de los estudiantes de quinto año de secundaria de Lima metropolitana no es ajena a este fenómeno, que se da en las audiencias a escala mundial por la proliferación de canales: abiertos y cerrados (de cable).

9. Que los jóvenes se autoafirman cuando dicen que no se identifican con los personajes que ven en sus programas de televisión porque no se parecen a ellos, esto tendría que ver con la proliferación de canales y programas.

10. Que los jóvenes de sexo masculino de colegios particulares muestran abiertamente una atracción hacia el sexo opuesto a través de los anuncios publicitarios que muestran a la «mujer objeto» en la televisión, y las estudiantes de colegios estatales viven la atracción hacia el sexo opuesto soñando con «el príncipe azul», que lo idealizan en los actores y cantantes que aparecen en los programas de televisión. 
Por tanto, se recomienda realizar talleres de «lectura crítica de los medios de comunicación», especialmente de la televisión; talleres de uso responsable del tiempo libre, talleres de autoestima y habilidades sociales, resolución pacífica de conflictos, así como talleres de igualdad de género a través de actividades extraescolares.

Asimismo, se recomienda realizar la promoción del voluntariado y el asociacionismo juvenil a fin de que los jóvenes escolares canalicen sus inquietudes y aspiraciones a través de estos canales, que favorezcan su participación ciudadana en el futuro.

\section{Bibliografía}

Alfaro, R. y S. Maccasi (1995). Seducidos por la tele: Huellas educativas en padres y niños. Lima: Calandria/ Ceeal/Save the Children.

Ander-Egg, E. (1996). Teleadictos y vidiotas en la aldea planetaria: ¿qué hace la televisión con nosotros? Buenos Aires: Lumen Humanitas.

Aparici, R.; García, A. y M. S. Valdivia (1996). La imagen. Madrid: Universidad Nacional de Educación a Distancia.

Charles, M. y G. Orozco (1990). Educación para la recepción: Hacia una lectura crítica de los medios. México: Trillas.

Hausner, L. y J. Schosberg (2000). Enseña a tu hijo a concentrarse. Barcelona: Espasa Libros.

Orozco, G. (1996). Televisión y audiencias: Un enfoque cualitativo. Madrid: Ediciones La Torre/Universidad Iberoamericana.

Postman, N. (1991). Divertirse hasta morir: El discurso público en la era del show bussiness. Barcelona: Ediciones La Tempestad.

Sartori, G. (1997). Homo videns. Madrid: Ediciones Santillana/Taurus.

Toffler, A. (1994). El cambio de poder. Barcelona: Plaza y Janes. 